\title{
DISTRIBUIÇÃO DO SISTEMA RADICULAR DO MARACUJAZEIRO-DOCE CULTIVADO COM ADUBAÇÃO QUÍMICA E ORGÂNICA ${ }^{1}$
}

\author{
MARCO ANTONIO TECCHIO ${ }^{2}$, ERVAL RAFAEL DAMATTO JUNIOR ${ }^{3}$, SARITA LEONEL ${ }^{4}$, CARLOS JORGE PEDROSO $^{5}$
}

\begin{abstract}
RESUMO - O experimento teve como objetivo avaliar a distribuição das raízes do maracujazeiro-doce (Passiflora alata Dryand), cultivado em Nitossolo Vermelho, sob adubação química e orgânica, em Botucatu-SP. Foram utilizadas plantas com 19 meses de idade, em produção, conduzidas em latada e com irrigação. Os tratamentos com fertilizantes químicos e esterco de curral curtido foram os seguintes: T1 (400 g de sulfato de amônia), T2 (2,5kg de esterco), T3 (5,0kg de esterco), T4 (7,5kg de esterco) e T5 (10,0kg de esterco), acrescidos de $200 \mathrm{~g}$ de termofosfato, $137 \mathrm{~g}$ de cloreto de potássio e $2,0 \mathrm{~kg}$ de calcário por planta, em todos os tratamentos, parcelados em duas aplicações. Foram empregadas 3 plantas por tratamento, sendo retiradas quatro amostras de cada uma, a 0-20 e 20-40 cm de profundidade e distância do tronco. Os resultados evidenciaram que não houve diferenças significativas entre os tratamentos para massa seca das raízes. Em todos os tratamentos, houve concentração das raízes a 0-20cm de distância do tronco. Nas parcelas com adubo orgânico, houve melhor distribuição das raízes em profundidade.
\end{abstract}

Termos para indexação: Passiflora alata (Dryand), raízes, fertilização, esterco.

\section{FRAGANT GRANADILLA ROOTS DISTRIBUTION CULTIVATED WITH ORGANIC AND CHEMICAL FERTILIZERS}

\begin{abstract}
The experiment had as purpose to evaluate the fragant granadilla (Passiflora alata Dryand) roots distribution, cultivated in Nitossolo Vermelho, under chemical and organic fertilization, in Botucatu/SP. It was utilized plants with 19 months, in production, driven in "latada" and with irrigation. The treatments with fertilizers chemical and manure were: T1 (400g ammonium sulfate), T2 (2,5kg of manure), T3 (5,0kg of manure), T4 (7,5kg of manure) e T5 (10,0kg of manure), enhanced with $200 \mathrm{~g}$ of termophospate, $137 \mathrm{~g}$ of potassium chloride and $2,0 \mathrm{~kg}$ of calcareous for plant, parceled in two applications. It was evaluated 3 plants by treatment, with four replications of each one, at $0-20$ and $20-40 \mathrm{~cm}$ of deep and distance of the stem. The results showed that there were no significant differences among the treatments for dry weight of the roots. In all the treatments there was concentration of the roots at $0-20 \mathrm{~cm}$ distance of the stem. The treatments with organic fertilizer had the best deep roots distribution.
\end{abstract}

Index terms: Passiflora alata (Dryand), roots, fertilization, manure.

O maracujazeiro-doce (Passiflora alata Dryand) vem despertando o interesse de produtores e ganhando importância econômica pelas qualidades gustativas de seus frutos, pelo uso medicinal da planta, pela possibilidade de adaptação a condições climáticas mais amenas, além da boa rentabilidade apresentada pela cultura nos plantios comerciais. A expansão dos cultivos tem gerado demanda por tecnologias de produção mais adequadas, capazes de elevar a produtividade dos pomares. Além disso, para uso da planta como fitoterápico, é exigido que os cultivos sejam realizados sob manejo orgânico.

No entanto, existem poucos estudos sobre aspectos botânicos e fisiológicos dessa frutífera, sendo que os existentes reportam principalmente sobre o florescimento da planta.

Em estudo sobre a distribuição das raízes do maracujá-roxo enxertado em maracujá-amarelo (Passiflora edulis f. flavicarpa), Kuhne (1965) concluiu que 73 a $85,5 \%$ de todas as raízes estavam concentradas entre 15 a $45 \mathrm{~cm}$ de profundidade. Com relação a distância, observou-se que elas estavam concentradas entre $30 \mathrm{a} 45 \mathrm{~cm}$ do tronco. As raízes estavam distribuídas quase uniformemente nas diversas profundidades estudadas.

Ocampo et al. (1994), estudando a distribuição do sistema radicular do maracujazeiro (Passiflora edulis f. flavicarpa) em um solo arenoso, encontraram a maior densidade de raízes na profundidade de $0-20 \mathrm{~cm}$ e numa distância de $51-100 \mathrm{~cm}$ da base da planta, indicando que as plantas, nessas condições, apresentam as raízes mais superficiais.

Também Kliemann (1986) e Medina et al. (1980) relatam que o sistema radicular do maracujazeiro-amarelo é considerado superficial, estando concentrado nos primeiros $30-40 \mathrm{~cm}$ de solo e num raio de $50 \mathrm{~cm}$, chegando essa porção de solo a sustentar 60 a $80 \%$ do sistema radicular do maracujazeiro. Os autores também concluíram que a maior taxa de crescimento das raízes foi verificada entre os 210 e 300 dias de idade, após o que tende à estabilidade.

A literatura refere-se ao maracujá-doce como planta altamente produtiva, que requer adubações fartas, porém equilibradas, para assegurar as quantidades necessárias de nutrientes para o crescimento das plantas e elevadas produções, confirmando a escassez de estudos sobre os níveis de fertilizantes e adubos orgânicos (Kavati \& Pizza Júnior, 2002). Nesse sentido, estudos sobre aspectos morfológicos da planta, como a distribuição do sistema radicular sob diferentes condições de manejo, são interessantes, na medida em que possam auxiliar e fornecer informações para a realização dos principais tratos culturais, como irrigação, calagem e adubação da cultura.

O presente trabalho teve como objetivo avaliar o efeito da adubação química e orgânica na distribuição das raízes do maracujazeirodoce, cultivado em Nitossolo Vermelho, em Botucatu-SP.

O trabalho foi conduzido em área do pomar do Departamento de Produção Vegetal - Horticultura da Faculdade de Ciências Agronômicas/UNESP, Câmpus de Botucatu - SP. As coordenadas geográficas locais, de acordo com Tubelis \& Salibe (1989), são: 2252'47" latitude $\mathrm{S}, 48^{\circ} 25^{\prime} 12^{\prime \prime}$ longitude $\mathrm{W}$ e altitude de $810 \mathrm{~m}$. O tipo climático predominante no local é o temperado, sem inverno seco, sendo a média das temperaturas mínimas de $18^{\circ} \mathrm{C}$ e a das máximas de $22^{\circ} \mathrm{C}$, com precipitação média anual de 1.314mm (Tubelis et al., 1972 e Curi, 1972). O solo da área foi caracterizado como unidade lageado-terra roxa estruturada, álica, textura argilosa, latossólica (Carvalho et al., 1983), atualmente Nitossolo Vermelho, segundo os critérios da Embrapa (1999).

O plantio das mudas no campo foi realizado no mês de janeiro de 2002. O espaçamento adotado foi de $2 \mathrm{~m}$ entre linhas e $4 \mathrm{~m}$ entre plantas, com uma área de $8 \mathrm{~m}^{2}$ planta $^{-1}$, sendo adotado o sistema de condução em latada. As dimensões das covas foram de 60 x 60 x $60 \mathrm{~cm}$.

A irrigação complementar, através do sistema de gotejamento localizado sob copa (Vasconcellos, 2000), iniciou-se 6 meses após o

\footnotetext{
${ }^{1}$ (Trabalho 155/2004). Recebido: 11/11/2004. Aceito para publicação: 17/08/2005.

${ }^{2}$ Pesquisador Científico do Centro de Frutas -IAC - Av. Luiz Pereira dos Santos, Bairro Corrupira - 13214-820 - Jundiaí-SP - tecchio@iac.sp.gov.br.

${ }^{3}$ Eng $^{\circ}$ Agr $^{\circ}$. Doutorando em Horticultura/FCA/UNESP.

${ }^{4}$ Prof $^{a}$. Dr ${ }^{\mathrm{a}}$. Departamento de Produção Vegetal/FCA/UNESP. Cx postal: 237, Cep: 18603-970. Botucatu-SP. Fone: (14) 3811-7172. Endereço eletrônico: sarinel@fca.unesp.br;

5 Técnico Agropecuário. Bolsista da Fapesp.
} 
plantio, na época constatada como de maior ocorrência de deficiência hídrica (julho/2002), com freqüência de 3 horas por dia, numa vazão de 2,64 litros/hora, sendo empregada quantidade uniforme para todas as plantas.

Quando as plantas estavam com 14 meses, foram colocados fertilizantes químicos e adubo orgânico, conforme os tratamentos descritos a seguir, os quais foram definidos conforme resultados da análise de solo e de acordo com a tabela de recomendação para maracujazeiro, do Boletim Técnico ${ }^{\circ} 100$ do IAC (1996): T1 (400g de sulfato de amônia), T2 (2,5kg de esterco de curral curtido), T3 (5,0kg de esterco de curral curtido), T4 (7,5kg de esterco de curral curtido) e T5 (10,0kg de esterco de curral curtido), acrescidos de $200 \mathrm{~g}$ de termofosfato, $137 \mathrm{~g}$ de cloreto de potássio e $2,0 \mathrm{~kg}$ de calcário por planta, em todos os tratamentos, parcelados em duas aplicações.

A avaliação da distribuição do sistema radicular foi realizada aos 19 meses após o plantio. De cada planta, foram retiradas quatro amostras a 0-20 e 20-40 cm de profundidade e distância do tronco, utilizando enxadão e pá reta, sendo que tais distâncias foram previamente estabelecidas, em função da área de molhamento do sistema de irrigação, no qual havia um gotejador em cada lado da planta, no sentido da linha de plantio. As amostras de solo de cada profundidade e distância do tronco apresentavam uma largura média de $40 \mathrm{~cm}$. A seguir, as amostras foram submetidas à lavagem cuidadosa, com auxílio de peneira, para a eliminação da terra aderida às raízes $\mathrm{e}$, posteriormente, foram colocadas em estufa de circulação de ar forçado a $65^{\circ} \mathrm{C}$, para secagem. A característica avaliada foi a massa seca média das raízes, expressa em $\mathrm{g}$ $\mathrm{dm}^{-3}$ de solo e em porcentagem.

Utilizou-se do delineamento experimental inteiramente casualizado, com 3 repetições, sendo cada parcela experimental representada por 3 plantas. Realizou-se análise de variância, teste de média e análise de regressão. Para comparar o efeito da adubação orgânica com a adubação química, realizou-se o teste Dunnett's, ao nível de $5 \%$, e para as doses de esterco de curral, realizou-se análise de regressão (Kronka \& Banzatto, 1992).

Os resultados obtidos evidenciaram que não houve diferença significativa entre os tratamentos com adubo orgânico e químico, para a massa seca das raízes e percentagem de raízes (Tabelas 1 e 2). No entanto, observou-se que, com a adubação química, houve um ligeiro aumento no volume de raízes $\left(10,85 \mathrm{~g} \mathrm{dm}^{-3}\right.$ de solo), quando comparado com os outros tratamentos.

Observou-se também que, em todas as amostragens, nenhum modelo de regressão foi significativo para expressar a massa seca de raízes e a percentagem, em função das doses de adubo orgânico.

Ressalta-se que a ausência de respostas significativas nos tratamentos pode ser devida ao alto coeficiente de variação verificado nos dados, possivelmente em função da dificuldade dessas amostragem. No entanto, comparando as médias das Tabelas 1 e 2, algumas considerações importantes podem ser feitas.

Em todos os tratamentos, houve maior concentração do sistema radicular a $0-20 \mathrm{~cm}$ de distância do tronco. Tais resultados estão de acordo com os obtidos por Akamine \& Girolami (1959), na África do Sul, onde a maioria das raízes estavam concentradas na profundidade de 0 $45 \mathrm{~cm}$, sendo formadas principalmente por raízes grandes (com diâmetro maior que $4 \mathrm{~mm}$ ) e à distância de $15-45 \mathrm{~cm}$ do tronco.

No Brasil, Carvalho et al. (1972), avaliando a distribuição do sistema radicular em plantas com 28 meses do plantio no campo, em Terra Roxa Estruturada, relataram que $73 \%$ das raízes pequenas estavam localizadas na profundidade de $20 \mathrm{~cm}$ e $68 \%$ do total das raízes, à distância de $60 \mathrm{~cm}$ do tronco.

Verificou-se que, nos tratamentos com adubo orgânico, houve melhor distribuição das raízes, a partir da dosagem de 5,0kg de esterco de curral curtido por planta. Os resultados apresentados na Tabela 1 mostram que, nos tratamentos T3, T4 e T5, com respectivamente 5,0; 7,5 e $10 \mathrm{~kg}$ de adubo orgânico planta ${ }^{-1}$, a profundidade do sistema radicular foi maior que no tratamento com adubo químico, sendo que, no tratamento $\mathrm{T} 4$, com 7,5kg de esterco de curral curtido, apresentou a maior porcentagem de raízes $(80,99 \%)$ a $20-40 \mathrm{~cm}$ de profundidade.

Tais resultados são interessantes, uma vez que a maior porcentagem de raízes em profundidade permite maior exploração do solo, favorecendo a absorção de água e nutrientes pelas plantas,

TABELA 1 - Resultados médios da massa seca das raízes em $\mathrm{g} \mathrm{dm}^{-3}$ de solo, de maracujazeiro submetidos a diferentes tratamentos com adubação orgânica e convencional. FCA/UNESP - Botucatu-SP, 2003.

\begin{tabular}{|c|c|c|c|c|c|}
\hline \multirow[t]{2}{*}{ Doses de adubo planta ${ }^{-1}$} & \multicolumn{2}{|c|}{$\begin{array}{l}0-20 \mathrm{~cm} \text { distante da planta } \\
\text { Profundidade }\end{array}$} & \multicolumn{2}{|c|}{$\begin{array}{l}\text { 20-40cm distante da planta } \\
\text { Profundidade }\end{array}$} & \multirow[t]{2}{*}{ TOTAL } \\
\hline & $0-20 \mathrm{~cm}$ & $20-40 \mathrm{~cm}$ & $0-20 \mathrm{~cm}$ & $20-40 \mathrm{~cm}$ & \\
\hline $400 \mathrm{~g}$ Sulfato de amônio & 4.56 & 4.18 & 0.98 & 1.14 & 10.85 \\
\hline $2,5 \mathrm{~kg}$ esterco & 4.06 & 2.95 & 1.59 & 1.69 & 10,29 \\
\hline $5,0 \mathrm{~kg}$ esterco & 1.59 & 3.78 & 0.25 & 0.59 & 6.20 \\
\hline $7,5 \mathrm{~kg}$ esterco & 1.26 & 7.75 & 0.17 & 0.58 & 9.75 \\
\hline $10,0 \mathrm{~kg}$ esterco & 2.02 & 4.78 & 0.57 & 0.83 & 8.19 \\
\hline CV $(\%)$ & 56,04 & 36,90 & 35,85 & 59,70 & 33,09 \\
\hline $\mathbf{F}$ & ns & ns & ns & ns & ns \\
\hline DMS & 4,17 & 4,98 & 0,79 & 1,62 & 8,82 \\
\hline
\end{tabular}

Médias seguidas pelas mesmas letras na coluna não diferem, pelo teste de Dunnet's, a 5\% de probabilidade.

TABELA 2 - Resultados médios da porcentagem (\%) de massa seca das raízes de solo, de maracujazeiro submetidos a diferentes tratamentos com adubação orgânica e convencional. FCA/UNESP - Botucatu-SP, 2003.

\begin{tabular}{|c|c|c|c|c|}
\hline \multirow[t]{2}{*}{ Doses de adubo planta ${ }^{-1}$} & \multicolumn{2}{|c|}{$\begin{array}{l}0-20 \mathrm{~cm} \text { distante da planta } \\
\text { Profundidade }\end{array}$} & \multicolumn{2}{|c|}{$\begin{array}{l}\text { 20-40cm distante da planta } \\
\text { Profundidade }\end{array}$} \\
\hline & $0-20 \mathrm{~cm}$ & $20-40 \mathrm{~cm}$ & $0-20 \mathrm{~cm}$ & $20-40 \mathrm{~cm}$ \\
\hline $400 \mathrm{~g}$ Sulfato de amônio & 41.78 & 39.36 & 9.20 & 9.66 \\
\hline $2,5 \mathrm{~kg}$ esterco & 38,13 & 28,61 & 16.36 & 16,90 \\
\hline $5,0 \mathrm{~kg}$ esterco & 26,20 & 60,24 & 3,93 & 6,62 \\
\hline $7,5 \mathrm{~kg}$ esterco & 11.19 & 80,99 & 1.75 & 6,06 \\
\hline $10,0 \mathrm{~kg}$ esterco & 20,91 & 61,35 & 6.29 & 11,45 \\
\hline CV (\%) & 41,95 & 23,37 & 35,38 & 45,86 \\
\hline $\mathbf{F}$ & ns & ns & ns & ns \\
\hline DMS & 35,17 & 38,90 & 9,06 & 15,50 \\
\hline
\end{tabular}

Médias seguidas pelas mesmas letras na coluna não diferem, pelo teste de Dunnet's, a 5\% de probabilidade. 
principalmente em condições desfavoráveis para o crescimento das raízes, como baixo $\mathrm{pH}$ na subsuperfície ou déficit hídrico.

Além disso, ressalta-se que a maior concentração das raízes a 0-20cm de distância do tronco permite inferências sobre a distribuição da adubação em cobertura, auxiliando o produtor a otimizar esta operação.

A distribuição do sistema radicular do maracujazeiro-doce apresentou concentração das raízes a uma distância de $0-20 \mathrm{~cm}$ do tronco, independentemente do sistema de adubação utilizado.

A melhor distribuição das raízes em profundidade foi verificada com a aplicação de adubo orgânico, na forma de esterco de curral curtido.

\section{REFERÊNCIAS}

AKAMINE, E.K.; GIROLAMI, G. Pollination and fruit set in the yellow passion fruit. Honolulu: Hawai Agricicultural Experimental State, 1959. 44p. (Boletim técnico 39).

BOLETIM TÉCNICO 100. Instituto Agronômico de Campinas (IAC). Campinas, 1996.285p

CARVALHO, A.M. de; ALOÍSIO SOBRINHO, J.; IGUE, T. Adubação mineral do maracujazeiro. Ciência Agronômica, São Paulo, v. 24, n. 6, p.412, 1972.

CURI, P.R. Relações entre evaporação medida pelo tanque IA-58 e evapotranpiração calculada pelas equações de Thornthwait $e$ Camargo, para o município de Botucatu. Botucatu. 1972. 88f. (Doutorado) - Faculdade de Ciências Médicas e Biológicas de Botucatu. Universidade Estadual Paulista, Botucatu, 1972.
EMBRAPA. Centro Nacional de Pesquisa de Solos. Sistema brasileiro de classificação de solos. Rio de Janeiro, 1999. 412p.

KAVATI, R.; PIZA JÚNIOR, C. de T. A cultura do maracujá doce. Campinas: CATI, 2002. 46p. (Boletim Técnico, 244).

KLIEMANN, H.J. Nutrição mineral e adubação de fruteiras tropicais. Campinas: Fundação Cargill, 1986. p.247-284.

KRONKA, S.N.; BANZATTO, D.A. Experimentação agrícola. Jaboticabal: FUNEP, 1992.247p.

KUHNE, F.A. Granadillas and their roots systems. Farming in South Africa, Pretoria, v.44, n.5, p.7, 1968

MEDINA, J.C.; GARCIA, J.L.M.; LARA, J.C.C.; TOCCHINI, R.P.; HASHIZUME, T.; MORETTI, V.A.; CANTO, W.L. do. Maracujá: da cultura ao processamento e comercialização. São Paulo: ITAL, 1980. 207p. (Frutas Tropicais, 9).

OCAMPO, A.M.L; LOZANO, S.E.; ESTRADA, M.E.V.; CAMPBELL,R.J. Root distribution of Passiflora edulis var. flavicarpa Proceedings of the Interamerican Society for Tropical Horticulture, Miami, v.38, p.139-141, 1994.

TUBELIS, A.; NASCIMENTO, F.J.L.; FOLONI, L.L. Meteorologia e climatologia. Botucatu: Faculdade de Ciências Médicas e Biológicas de Botucatu, UNESP, 1972. v.3, p.344-362. (Mimeografado).

TUBELIS, A.; SALIBE, A.A. Relações entre produção de laranjeira "Hamlin" e as precipitações mensais no altiplano de Botucatu. Pesquisa Agropecuária Brasileira, Brasília, v.23, p.801-806, 1989.

VASCONCELLOS, M.A. da S. Maracujazeiro doce: sistema de produção. Informe Agropecuário, Belo Horizonte, v. 21, n. 206, p. 76-80, 2000. 